\title{
Assessment of underground wine cellars using geographic information technologies
}

\author{
T. Herrero , E. Pérez-Martín-, M. A. Conejo-Martin , J. L de Herrera , \\ A. Ezquerra-Canalejo- and J. Velasco-Gómez-
}

Geographic information technologies (GIT) are essential to many fields of research, such as the preservation and dissemination of knowledge of cultural heritage buildings, a category which includes traditional underground wine cellars. This paper presents a methodology based on research carried out on this type of rural heritage building. The data were acquired using the following sensors: EDM, total station, close range photogrammetry and laser scanning, and subsequently processed with a specific software which was verified for each case, in order to obtain a satisfactory graphic representation of these underground wine cellars. Two key aspects of this work are the accuracy of the data processing and the visualisation of these traditional constructions. The methodology includes an application for geovisualising these traditional constructions on mobile devices in order to contribute to raising awareness of this unique heritage.

\section{Research aims}

The main objective is to find an efficient method to document underground wine cellars, as singular elements of the heritage and culture of the Iberian Peninsula. The aim of this research is to document graphically and cartographically both the interior and exterior of underground wine cellars, and to obtain the necessary metric and volumetric data using a variety of sensors for the comprehensive study of these traditional structures. As a support for the dissemination of the knowledge of this heritage, we propose the use of GIT applications to allow their geovisualisation on mobile devices.

\section{Introduction}

The considerable advances in processing, memory capacity and new technology of the graphics cards on computers today allow a large quantity of $3 \mathrm{D}$ data to be processed from various different sensors. This mass processing of 3D data represents a major step forward in the field of geovisualisation applied to the study of cultural heritage (Chane et al, 2013; Lichti et al, 2008; Lerma et al, 2010). Techniques using terrestrial laser scanners provide accurate high-quality 3D models with a far greater level of detail (Caprioli et al, 2011; Guarnieri et al, 2011). However, a methodology is required for their use in the documentation of cultural heritage. Accuracy in the data collection and processing stages guarantees 3D models that provide an optimal visualisation of the project.

The procedures for 3D modelling and visualisation and animation software are in a state of constant development (Remondino, 2011) and have been continually applied in the documentation and dissemination of cultural heritage (Fuentes et al, 2010; Ruther et al, 2009). The opportunity to highlight the importance of the cultural heritage in the study area using these new technologies and interactive multimedia environments (Guarnieri et al, 2010) contributes an intangible added value to this heritage (Perez-Martin et al, 2011)

The European Union's rural development policies described in the LEADER (Liaison Entre Actions de Développement de l'Économie Rurale) and PRODER (Rural Development Programs that have been implemented exclusively in Spain) programmes promote the preservation of these traditional constructions. In Spain, the National Heritage organisation and the various regional laws support the preservation of this ancestral legacy as a sustainable resource in the tourism and culture sector.

Spain is home to a series of constructions in rural environments known as underground wine cellars. These heritage buildings are closely linked to traditional ways of life, and deserve to be studied and protected before they disappear. As a result of emigration from rural areas and the mechanisation of the majority of agricultural processes, these traditional constructions 

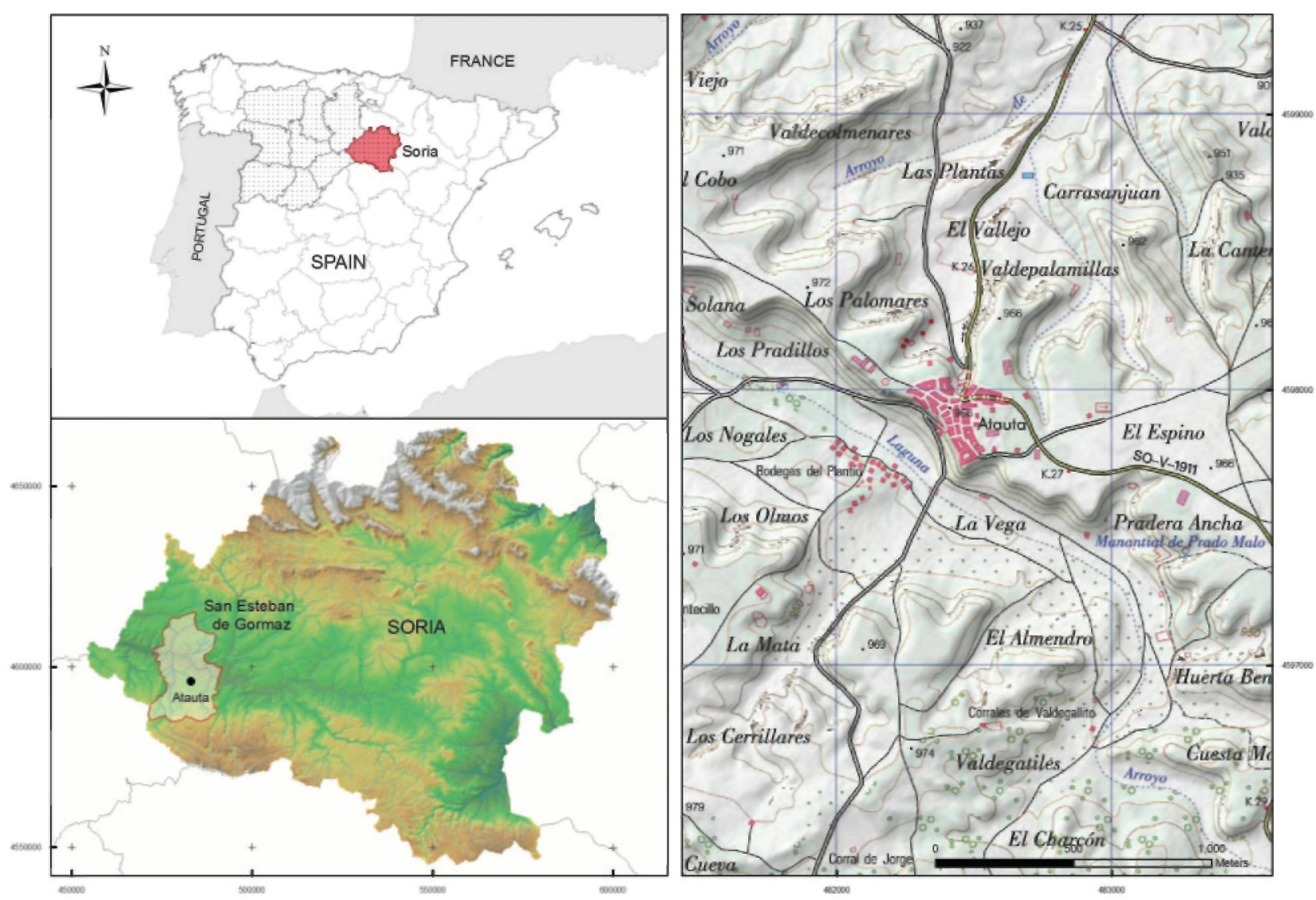

1 Location of Atauta (Soria)

have fallen into disuse, leading to their subsequent deterioration.

This study is part of the BIA2004-03266 research project entitled 'Underground wine-cellar construction. Eco-construction systems for quality wines', one of the objectives of which is to find a low cost and efficient method of inventorying underground wine cellars.

It is intended that the methodology used in this research will serve to make a general inventory of the underground cellars, particularly in Spain. All the numeric, alphanumeric, graphic and cartographic information so obtained should be incorporated into the various property and heritage registers. The data collected, such as property, land use, extension, volume, 2D and 3D plane and location, will contribute useful information to the current General Property Register.

There are listed cellars all over Spain, and particularly in the southeast of the Iberian Peninsula (Aranda, 2003). Studies have been carried out describing the various typologies of the underground cellars in the Ribera de Duero region, one of Spain's traditional wine producing areas (Fuentes Pardo and Guerrero, 2006). The knowledge of a heritage site requires the collection of specific information: a reconnaissance, a preliminary or approximate study, and a more detailed study. This article aims to analyse the various levels proposed by Patias and Santana (2011) based on the indications of Letellier (1995), although with extensive development of the level of detail on the heritage site. The proposals for a methodology for the re-utilisation of rural constructions include a systematic description of principles for cataloguing them in regional databases (Fuentes, 2010). This research is designed to respond to the urgent need to graphically represent these underground cellars in order to catalogue them and conduct exhaustive metric and volumetric studies.

Wine has traditionally been produced in wine cellars that are almost invariably built below ground level. They typically have a vault or entrance tunnel ending in a door to the outside, and an underground space where the wine is fermented, consisting of a gallery about $2 \mathrm{~m}$ high and with a length of between 5 and $20 \mathrm{~m}$. The entrance is north facing in order to favour ventilation, and there are normally one or more chimneys, known as 'zarceras'.

\section{Site description}

Atauta is a small village in the province of Soria (Castile-León, Spain) (Fig. 1). The wine cellars in Atauta represent the most numerous and best-conserved collection of this traditional architecture commonly found throughout the Ribera de Duero region.

Some of the underground wineries in the Ribera del Duero region date from the 15 th -16 th centuries (Maria Fuentes 2010).

The cellars in this study are located to the southwest of the village of Atauta, in a terrain with a varied geology comprising some 20 different types according to their composition, coarseness, nutrient richness, etc. There is a predominance of sandy, calcareous, silt and clay soils.

The study area stands at $950 \mathrm{~m}$ above sea level, and supports wine producing practices that date from 400 to 500 years ago. The orography consists of mountain slopes, a valley and a flat plain on a hill.

The climatology of the area has a continental character with a Mediterranean influence, and the average 


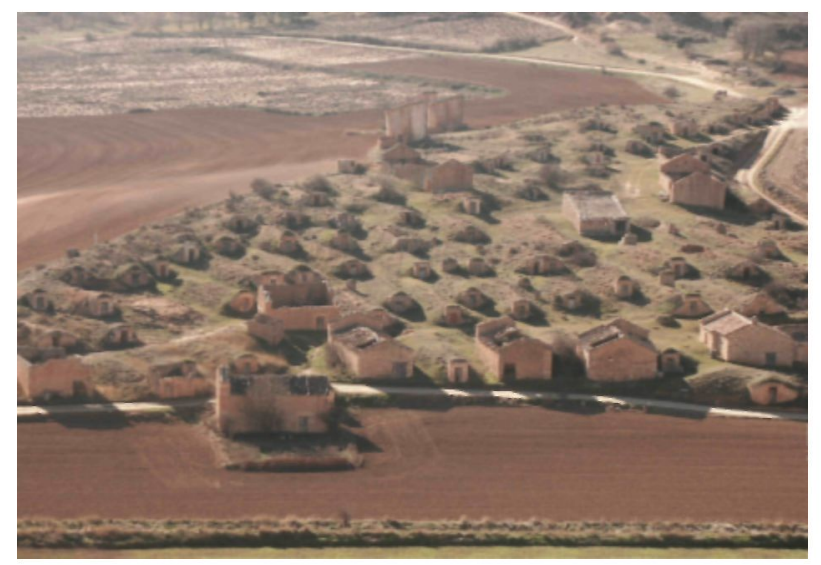

2 Underground wine cellars in Atauta (Soria)

rainfall ranges from 450 to $550 \mathrm{~mm}$ a year. Inside the underground cellars the high relative humidity of over 85 or $90 \%$ serves particularly to minimise evaporation loss and ensure a uniform year-round cool temperature of between $7{ }^{\circ} \mathrm{C}\left(45^{\circ} \mathrm{F}\right)$ and $13^{\circ} \mathrm{C}\left(55^{\circ} \mathrm{F}\right)$, long considered the optimum for aging high quality wines (Silvia and Ignacio, 2005).

Located on a gentle slope above the valley of Atauta, over an area covering 1.9 hectares, there are 141 underground wine cellars, 9 wine presses ('lagares'), 15 smaller wine presses ('lagaretas'), 3 castles and 4 dovecotes (Fig. 2).

\section{Characteristics}

There is a growing interest in the representation and visualisation of the real world using $3 \mathrm{D}$ tools. This is done today using the $3 \mathrm{D}$ property databases applied in national property registers (Aydin, 2008).

The underground wine cellars in Atauta belong to section 60, parcel 5676 (1.49 hectares) and section 65, parcel 5477 (0.38 hectares). They are declared as having agricultural use in the General Property Register (Fig. 3).

The constructions adjoining the underground wine cellars built on the surface also appear in the register, and are classified as 'undeveloped land, works of urbanisation and landscaping'. The remaining underground cellars are not registered.

The intention is for this site to be declared an 'ethnological site', a category considered under Law 12/2002 on Cultural Heritage of the Castile-León region. This law considers a Property of Cultural Interest (BIC) to be an 'ethnological site', consisting of any site or territory transformed by human action, in addition to series of both grouped and dispersed constructions, and installations associated with traditional ways of life (Pardo et al, 2007).

\section{Methodology}

The plan for the development of this research (Fig. 4) is based on the use of geovisualisation GIT for the representation of underground wine cellars as the optimum method for compiling an inventory of these unique spaces (Achille et al, 2011). Different sensors were assessed for data collection: topographical (total station) and innovative 3D techniques (laser scanner and close range photogrammetry). By comparing the readings from each sensor we obtain the data that allow us to assess the most efficient method for documenting and inventorying underground wine cellars. The Geographic Information Systems (GIS) proposed in the methodology is implemented with the data and information obtained. In order to visualise the information and promote the knowledge of these constructions, an application (API) for the web environment and mobile devices was created using ArcGIS.

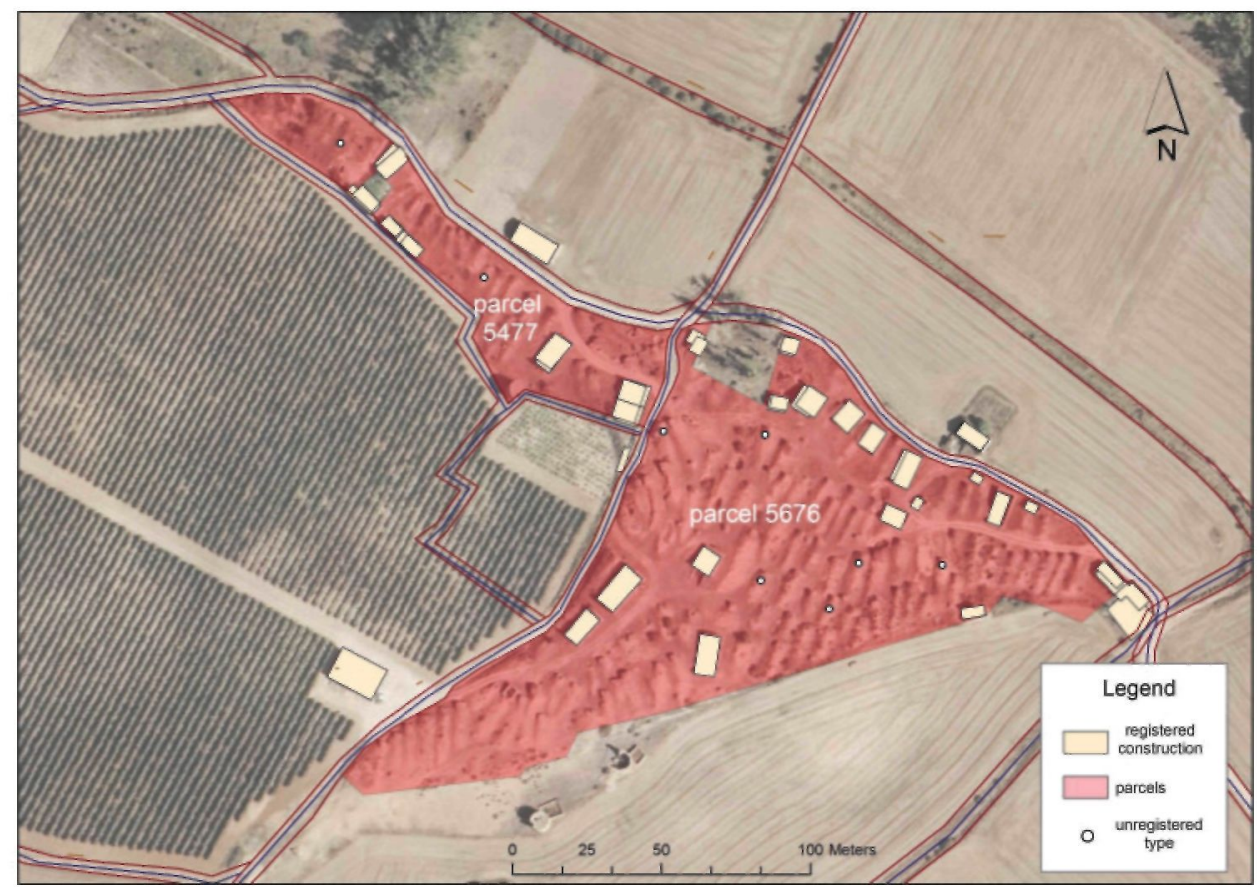

3 Constructions declared in the General Property Register 


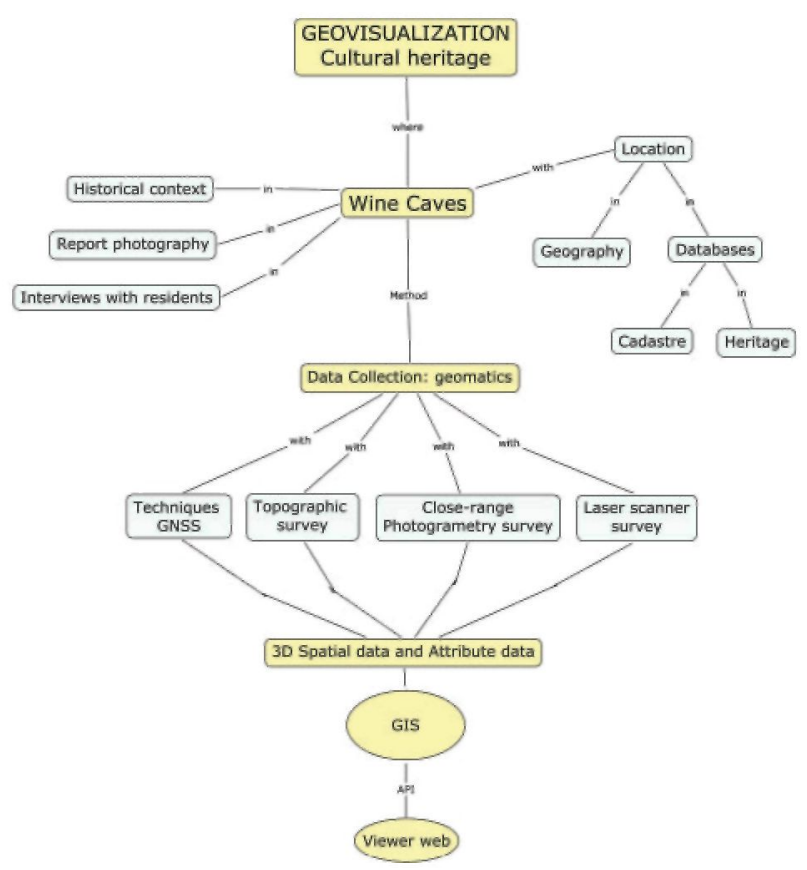

4 Diagram of methodology followed

\section{Measuring underground wine cellars: topographic survey}

The advances in the performance of total station such as non-prism measuring, robotics, camera and scanning functions have enabled this technology to be used for the documentation of cultural heritage (Scherer and Lerma, 2009). This GIT technique is used following the conventional method for survey accuracy.

The 'Atalaya' vertex in the National Geodesic Network has been used to georeference the topographic works in Spain's official geodetic reference system (European Terrestrial Reference System 1989 - ETRS89). A digital inventory was created using a reference point at the access to each underground wine cellar for the topographic mapping of the interior of each one. A conventional topographic map based on a closed polygonal was made of the area outside each underground wine cellar. An interior map was created using various stations to obtain the necessary planimetric and altimetric points to represent all the different spaces: access vault, corridor and the various rooms. The instrumentation used was a Pentax R-325N Total Station (Fig. 5) equipped with a laser sensor for nonprism readings.
Calculations were made for the graphic representation of each underground cellar, obtaining maps, longitudinal profile and cross sections (Fig. 6). The total volume of earth supported by the underground wine cellar was calculated based on surface differences (MDT), and the total capacity (volume) of the interior of the construction was obtained.

Aging wine involves maintaining the atmospheric conditions in a suitable space over a certain period of time. Underground cellars can provide these constant conditions. The volume of earth supported by the wine cellar and the air it contains is directly related with hygrothermal behaviour and its influence on the atmosphere in the cave (Silvia and Ignacio, 2005).

\section{Measuring underground wine cellars: close range photogrammetry survey}

Another GIT used to document cultural heritage that we assess in this paper is close range photogrammetry. Recently, methodologies have been applied to create accurate models using digital images (Barazzetti et al, 2011; Salonia et al, 2009). This method consists of the following steps: calibration and orientation of the camera, point measurement of the images and the generation of 3D point clouds, generation of the surface and the application of textures (Sansoni et al, 2009).

Different coloured markers were placed at key points to define the structure of the model to be represented. Circular targets are ideal because most software can actually assist in finding the centre of the target very accurately, far better than human error will allow. The different colours are used to define the structure of the underground cellar. The markers are made of expanded polystyrene and have a diameter of $60 \mathrm{~mm}$ (Fig. 7).

After visiting the reference wine cellar, the points from which the different image captures were to be made were located to give an overlap of at least $50 \%$, and with six common markers between the photographs. One of the difficulties encountered was the narrowness of the space to be mapped. All the images obtained were uploaded to the monoscopic digital photogrammetric station and processed with Photomodeler software (http://www. photomodeler.com/) to process the $3 \mathrm{D}$ reconstruction. The process of calibrating the camera, placing and referencing the markers used in the fieldwork and the subsequent internal and external orientations of the images generates a report on the whole procedure and produces a three-dimensional representation of the real space (Fig. 8). A knowledge of the structure and material of the underground cellar makes it possible to
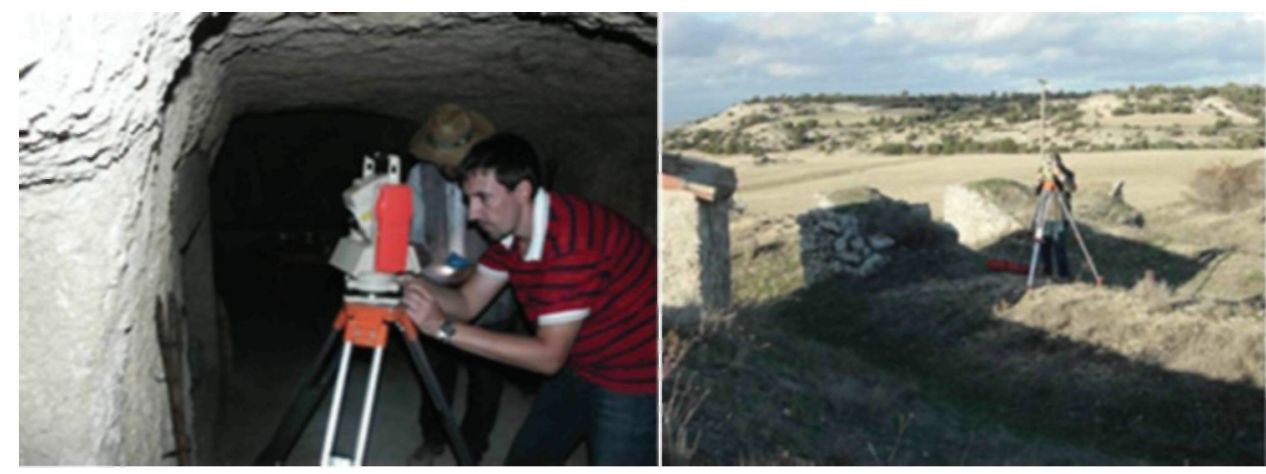

5 Topographic mapping with Pentax R-325N Total Station 


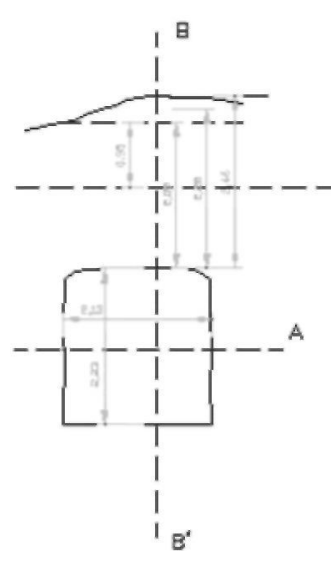

"Ap-alinar"
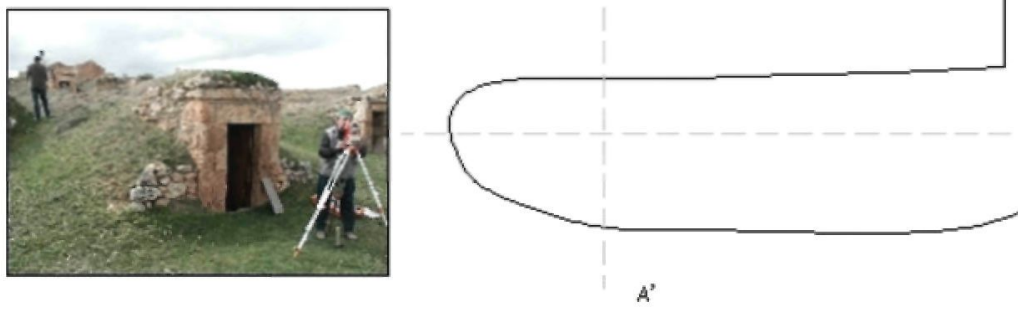

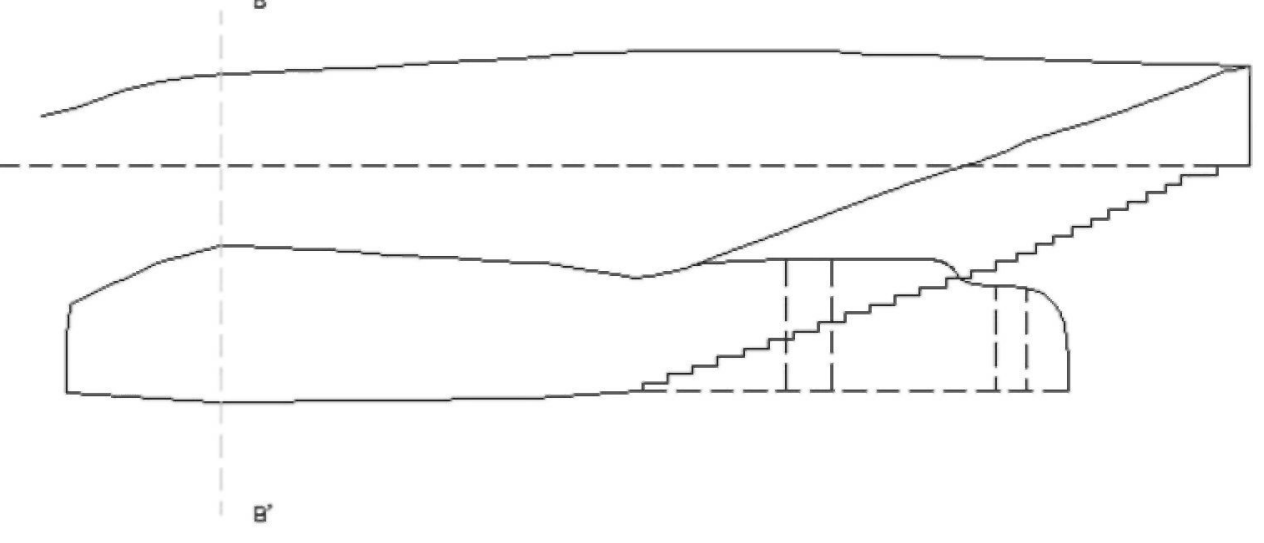

6 Plan and profile of underground wine cellar 'Apolinar'

study its condition, determine whether the structure is in need of support, and analyse any possible deformations.

The texture map is generated to give a realistic appearance to the three-dimensional model. The 3D modelling of the interior and exterior of the historic heritage was carried using the same methodology.

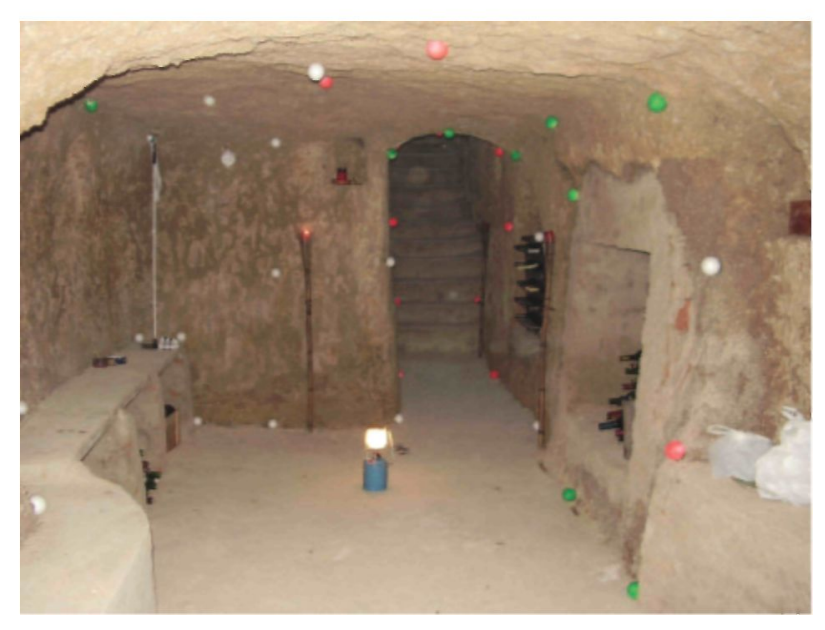

7 Position of markers

\section{Measuring underground wine cellars: laser scanner survey}

The introduction of terrestrial laser scanning (TLS) devices in the field of measuring has increased the possibility of obtaining more accurate and complete 3D models of objects (Sansoni et al, 2009). Data acquisition with laser scanning devices is also extremely fast. However, particular care must be taken when analysing, processing and modelling the data from the laser scanner, as they often have a high presence of noise which must be eliminated before processing begins (Fig. 9). As the spaces occupied by the wine cellars have complex and irregular geometric forms, a number of scans are required which must be georeferenced by identifying at least three homologous points in the overlapping area from two consecutive scans. The program makes three rotations and three translations in order to transfer the position of all the points to the single reference system for the whole work.

The underground wine cellar -'Apolinar'- in the study was scanned with the laser $\mathrm{Z}+\mathrm{F}$ IMAGER 5010 (Table 1), taking six scans from three different locations (Fig. 10).

The mapping resolution was designed based of the underground wine cellar, varying the distance from 0.40

Table 1 Characteristics of $Z+F$ Imager 5010 laser scanner

\begin{tabular}{lllllll}
\hline & $\begin{array}{l}\text { Sensor } \\
\text { weight } / \mathrm{kg}\end{array}$ & $\begin{array}{l}\text { Minimum } \\
\text { distance } / \mathrm{m}\end{array}$ & $\begin{array}{l}\text { Resolution } \\
\text { range/mm }\end{array}$ & $\begin{array}{l}\text { Data acquisition } \\
\text { rate }\end{array}$ & $\begin{array}{l}\text { Vertical field } \\
\text { of view } /{ }^{0}\end{array}$ & $\begin{array}{l}\text { Horizontal field } \\
\text { of view } /^{0}\end{array}$ \\
\hline $\mathrm{Z}+\mathrm{F}$ Imager & 9.8 & 0.3 & 0.1 & Max. 1.016 million pixel/s & 320 & 360 \\
\hline
\end{tabular}




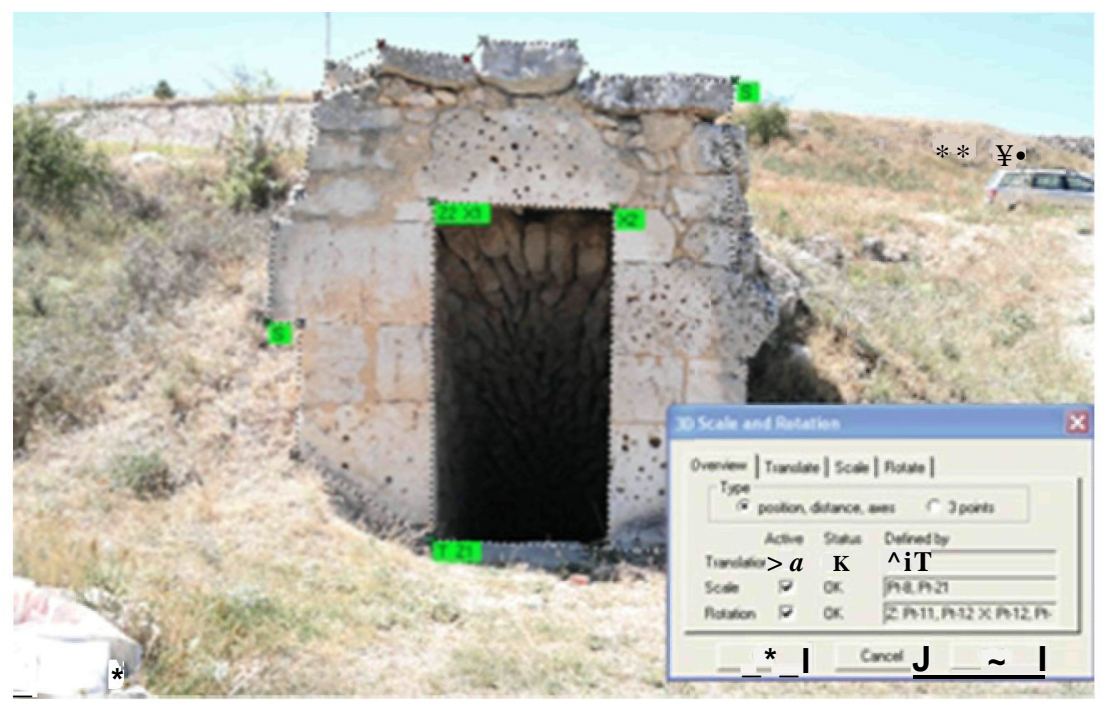

8 Referencing and exterior triangulation

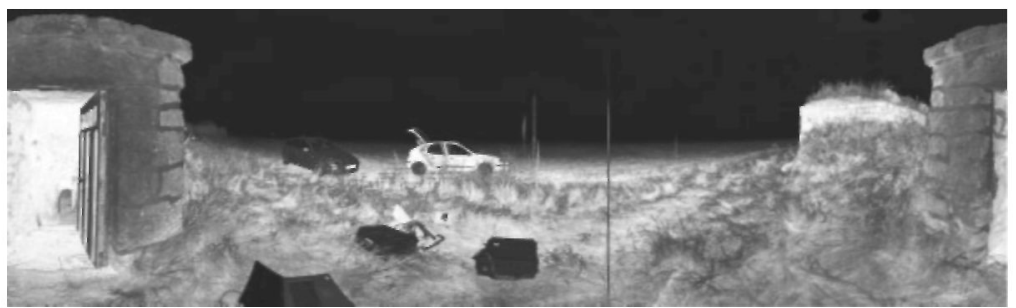

\section{Data collection with laser scanning}

to $6 \mathrm{~m}$ with a accuracy of $20 \mathrm{~mm}$. In order to validate the methodology, we considered an optimum ratio between the final accuracy obtained and the efficiency the data collection. The laser scanner was configured so that the point cloud and the resulting $3 \mathrm{D}$ model were accurate to the centimetre. We consider this accuracy to be sufficient for the graphic representation of the underground wine cellars in this study.

The JRC Reconstructor software was used. It has a broad capacity for handling three-dimensional data from historical and cultural sites. The estimated time spent on the different stages of processing the 3D model is shown in Table 2. The different 3D grid point clouds were georeferenced, and a range of filters were used to

Table 2 Estimate of time spent in different stages of processing of 3D model

\begin{tabular}{lr}
\hline Laser scanner survey & Time/h \\
\hline Data collection with laser scanning & $2: 00$ \\
Software reconstructor & \\
LiDAR data importing & $0: 30$ \\
Point cloud colour editing & $0: 20$ \\
Point cloud filtering and editing & $0: 25$ \\
Meshing and mesh simplification & $0: 25$ \\
Linear distances, areas and volumes, link to AutoCAD $0: 20$ \\
Simplifying mesh or point cloud & $0: 10$ \\
Cut and fill volumes & $0: 30$ \\
Orthophoto using high resolutions textured models & $0: 40$ \\
3D Model fly through video & $0: 40$ \\
Total & $6: 00$ \\
\hline
\end{tabular}

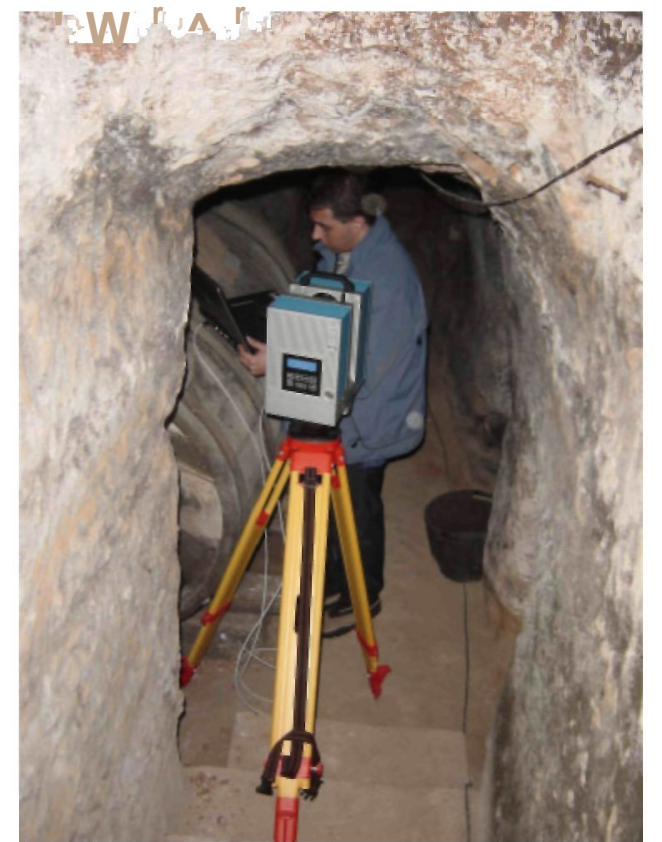

10 Data collection with $Z+F$ Imager 5010 laser scanner

minimise the noise, and a photorealistic three-dimensional model was created.

The 3D model enabled us to obtain the cross-section from the cutting plane containing the zone of the steps and the transverse profiles of the different areas of the underground wine cellar in the study. The transverse profiles indicate the height of the underground cellar 


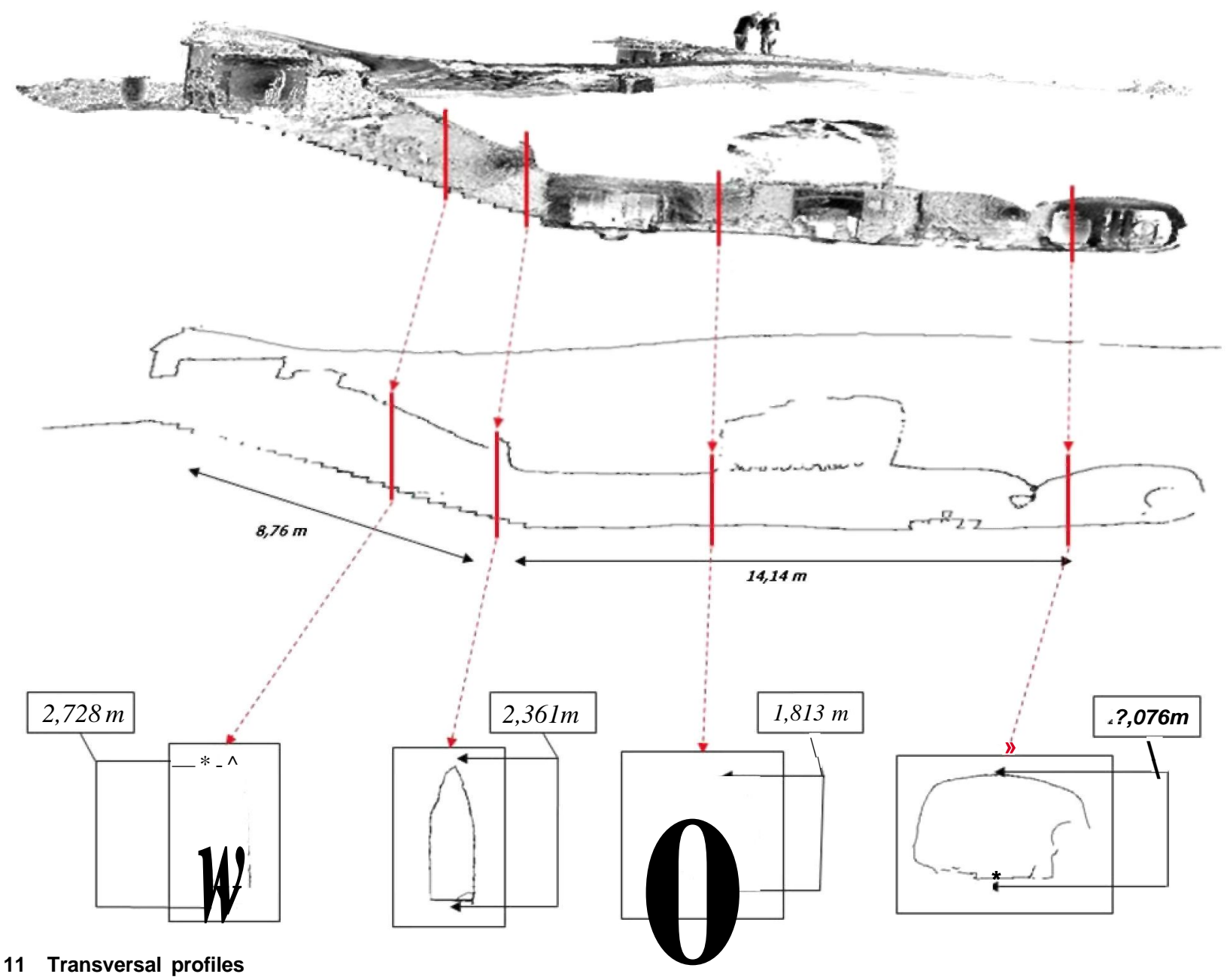

and allow calculation of the volume of earth supported (Fig. 11).

Subsequently orthophotos were obtained of the entrance to the underground wine cellar. Texture mapping is required in order to achieve photorealistic results. This involves georeferenced images taken by a calibrated digital camera on the 3D model (created by the scanner) and processed in order to blur/soften shifts in contrast and lighting (Fig. 12). The orthophotograph of each underground cellar will be incorporated into the General Property Register to provide additional information on the state of each property.

A series of virtual animations were obtained for use as a product for dissemination and preservation, and consisting of a route around the inside and outside of the underground wine cellar (Fig. 13).

\section{Results}

Table 3 shows the comparative analysis of the GIT used to represent a typical underground cellar. Using the GIT

technique for conventional surveying, it took five hours to represent the exterior and interior of the underground cellar. Few data were captured with this technique and a 3D model was generated with an accuracy of $80 \mathrm{~mm}$. Using the GIT technique for the close range photogrammetry survey took $7 \mathrm{~h}$ and involved a laborious data processing stage, with a final accuracy of around $30 \mathrm{~mm}$. The time taken to reconstruct the underground wine cellar with monoscopic digital photogrammetric station was two hours of data collection and another $4 \mathrm{~h}$ of data processing, with an accuracy of about $20 \mathrm{~mm}$.

The profiles and volumes were calculated using the 3D model generated by laser scanner. Due to the accuracy obtained for the 3D models created with the other techniques evaluated, topographic survey and close range photogrammetry survey, these were discarded for these calculations. The calculation was made by comparing the two surfaces by means of digital elevation models. The result is around $30-40 \mathrm{~m}^{3}$ of earth supported by an underground cellar. These data are

Table 3 Comparative analysis techniques GIT: accuracy obtained in relation with time

\begin{tabular}{llll}
\hline & Data collection/h & Data processing/h & 3d model accuracy/mm \\
\hline Topographic survey & $5: 00$ & $5: 00$ & $\mathbf{8 0}$ \\
Close range photogrammetry & $7: 00$ & $4: 00$ & $\mathbf{3 0}$ \\
survey & $2: 00$ & $\mathbf{4 : 0 0}$ & $\mathbf{2 0}$ \\
Laser scanner survey & & \\
\hline
\end{tabular}



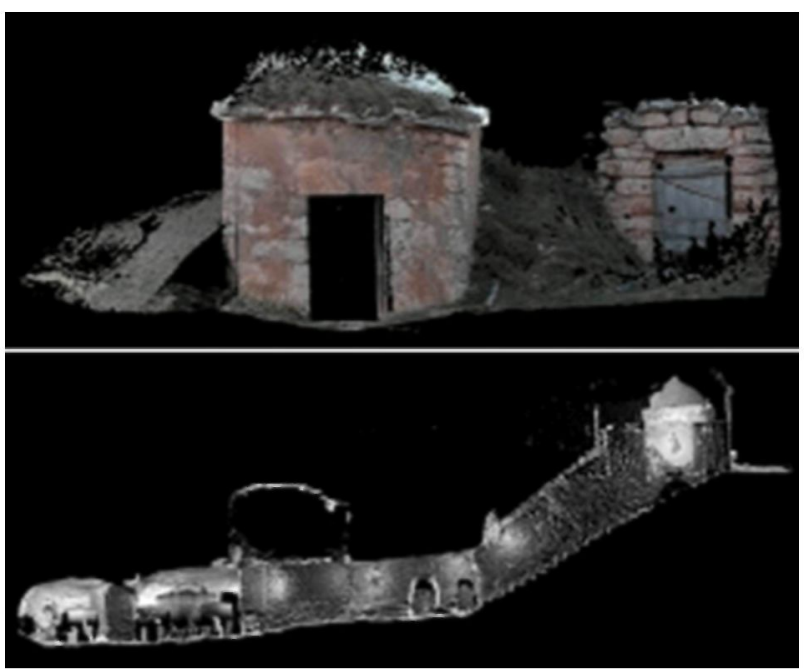

12 Texture mapping

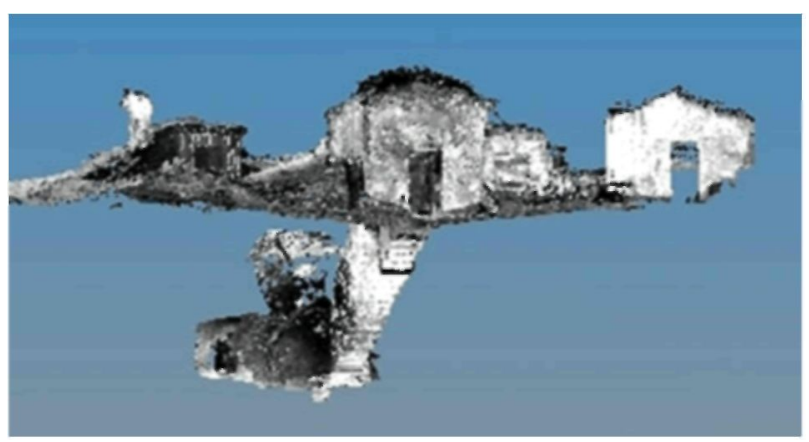

13 Virtual animation frame (JRC Reconstructor software)

used in subsequent studies of hygrothermal behaviour and its influence on the atmosphere of the underground cellar.

The results obtained have enabled us to conduct studies on the climate conditions inside the underground wine cellar in order to determine the quality of the wines (Silvia and Ignacio, 2005). For centuries man has dug out underground caves in which to produce and age wine. Heat inertia and the earth's properties confer thermal stability and the necessary conditions for wine conservation with zero energy costs (Mazarron and Canas, 2009).

We consider that the dissemination of cultural heritage is an essential factor for rural development in the study area. An application (API) was designed for the web environment and mobile devices (http:// www.gesypupm.com/\#!en-blanco/cp92) together with an explanatory video with information on this heritage element (http://youtu.be/G9nPEBC47ZA). All research results are available on the web application: maps, profiles, orthophotos, photographs and volumetric data. All the ideas or projects to be developed should be geared towards the reutilisation and adaptation of these spaces for new activities (Fuentes et al, 2010) in order to guarantee their preservation.

\section{Conclusions}

The challenge of this research is to make use of advanced technologies for data collection in underground wine cellars. This is a cultural heritage with a unique morphology, with a very narrow entrance, and different branches of varying depths. These features reduce the efficiency of close range photogrammetry. After assessing the underground wine cellars using GIT, it was found that the laser scanner as a rapid and accurate field technique for representing unique spaces, and although the post-processing time is high, it should be seen as the optimum tool for creating a digital inventory of underground wine cellars. We believe this study to be a best practise methodology, because of the high accuracy obtained in relation with the time spent on its development.

Currently, heritage archives and property registers do not contain 3D information. The methodology used in this research responds to this need. The accuracy obtained in the 3D model of the underground cellar using the laser technique is adequate for use in the databases of the General Property Register.

\section{Acknowledgements}

This study was supported by the project BIA2004-03266. Pru Brooke-Turner revised the English style. We really appreciate the positive reviews of two anonymous reviewers that notably enhanced the scientific quality of the work.

\section{References}

Achille, C, Fassi, F., Lombardini, N., Gaudio, F. and Galbusera, L., 2011. Survey of the archeological site of Nemi. A training experience. Paper presented to Proceedings of the XXIII CIPA Symposium, Prague, Czech Republic.

Aranda, F., 2003. Materia prima: arquitectura suhterrdnea excavada en Levante. Ediciones Generales de la Constructión edn.

Aydin, C. C, 2008. Usage of underground space for 3D cadastre purposes and related problems in Turkey, Sensors, 8(11), pp.6972-83.

Barazzetti, L., Binda, L., Scaioni, M. and Taranto, P., 2011. Photogrammetric survey of complex geometries with low-cost software: Application to the 'Gl ' temple in Myson, Vietnam, Journal of Cultural Heritage, 12(3), pp.253-62.

Caprioli, M., Minchilli, M. and Scognamiglio, A., 2011. 'Experiences in photogrammetric and laser scanner surveing of architectural heritage', paper presented to XXIII CIPA Symposium, Prague, Czech Republic.

Chane, C S., Schiitze, R., Boochs, F. and Marzani, F. S., 2013. Registration of 3D and multispectral data for the study of cultural heritage surfaces, Sensors, 13(1), pp. 1004-20.

Fuentes, J. M., Gallego, E., Garcia, A. I. and Ayuga, F., 2010. New uses for old traditional farm buildings: the case of the underground wine cellars in Spain, Land Use Policy, 27(3), pp. $738^{\wedge} 48$.

Fuentes Pardo, J. M. and Guerrero, I. C, 2006. Subterranean wine cellars of Central-Spain (Ribera de Duero): an underground built heritage to preserve', Tunnell. Underground Space Technol, 21(5), pp. $475-84$

Guarnieri, A., Pirotti, F. and Vettore, A., 2010. Cultural heritage interactive 3D models on the web: An approach using open source and free software, Journal of Cultural Heritage, 11(3), pp.350-3.

Guarnieri, A., Vettore, A., Camarda, M. and Domenica, C, 2011. Automatic registration of large range datasets with spin-images. Journal of Cultural Heritage, 12(4), pp.476-84.

Letellier, R., 1995. Recording, documentation and information management. Guidelines for world heritage sites', In U. Hull: ICCROM, ICOMOS: Heritage Recording Services of Public Works Canada (ed.)

Lichti, D., Pfeifer, N. and Maas, H.-G., 2008. ISPRS Journal of Photogrammetry and Remote Sensing theme issue 'Terrestrial Laser Scanning'. Isprs Journal of Photogrammetry and Remote Sensing, 63(1), pp.1-3.

Luis Lerma, J., Navarro, S., Cabrelles, M. and Villaverde, V., 2010 Terrestrial laser scanning and close range photogrammetry for $3 \mathrm{D}$ archaeological documentation: the Upper Palaeolithic Cave of Parpallo as a case study. Journal of Archaeological Science, 37(3), pp.499-507. 
Maria Fuentes, J., 2010. Methodological bases for documenting and reusing vernacular farm architecture, Journal of Cultural Heritage, $11(2)$, pp. 119-29.

Mazarron, F. R. and Canas, I., 2009. Seasonal analysis of the thermal behaviour of traditional underground wine cellars in Spain Renewable Energy, 34(11), pp.2484-92.

Pardo, J. M. F., Delgado, C. J. and Cañas, I., 2007. Construcciones agrarias tradicionales en la Ribera del Duero soriana, Asociación Tierras Sorianas del Cid.

Patias, P. and Santana, M., 2011. Introduction to heritage documentation. In E. Stylianidis et al. eds., CIPA Heritage Documentation. Best practices and applications, CIPA, vol. XXXVIII, p. 105.

Perez-Martin, E., Herrero-Tejedora, T. R., Gómez-Elviraa, M. A., Rojas-Solab, J. I. and Conejo-Martina, M. A., 2011. Graphic study and geovisualization of the old windmills of La Mancha (Spain). Applied Geography, 31(3), pp.941-9.

Remondino, F., 2011. Heritage Recording and 3D modeling with photogrammetry and 3D scanning. Remote Sensing, 3(6), pp. 1104-38.
Ruther, H., Chazan, M., Schroeder, R., Neeser, R., Held, C, Walker, S. J., Matmon, A. and Horwitz, L. K., 2009. Laser scanning for conservation and research of African cultural heritage sites: the case study of Wonderwerk Cave, South Africa, I. Archaeol. Sci., 36(9), pp. 1847-56.

Salonia, P., Scolastico, S., Pozzi, A., Marcolongo, A. and Messina, T.L., 2009. Multi-scale cultural heritage survey: Quick digital photogrammetric systems. Journal of Cultural Heritage, 10, pp.E59-E64.

Sansoni, G., Trebeschi, M. and Docchio, F., 2009. State-of-the-art and applications of 3D imaging sensors in industry, cultural heritage, medicine, and criminal investigation. Sensors, 9(1), pp.568-601.

Scherer, M. and Luis Lerma, J., 2009. From the conventional total station to the prospective image assisted photogrammetric scanning total station: comprehensive review. Journal of Surveying Engineering-Asce, 135(4), pp. 173-8.

Silvia, M. O. and Ignacio, C. G., 2005. Comparison of hygro-thermal conditions in underground wine cellars from a Spanish area. Building and Environment, 40(10), pp. 1384-94. 